\title{
Ni pobres ni incluidos: ¿nueva cuestión social? ${ }^{1}$
}

\author{
MANUEL CANALES C. ${ }^{2}$
}

\section{Resumen}

El texto siguiente ensaya la formulación de un conjunto de cuestiones sociales emergentes, dotadas de nuevos conflictos y estructuras, pero ancladas también en persistentes bases culturales. Es así como se comienza proponiendo un análisis de lo que estaba después de la pobreza, y que se analiza como una fractura por crisis de expectativas de promoción social. Se trata de comprender las formas que adopta la estratificación en el Chile de hoy y los nuevos conflictos que estas nuevas formas suponen. A la vez, se realiza un avance sobre una cuestión relevante de tematizar con mayor énfasis: la cuestión social en el marco de las formas territoriales de distribución de las poblaciones en Chile, donde una inadecuación entre lo administrativo y la realidad material se hace evidente. Finalmente, se aborda la cuestión de la discriminación y del autoritarismo, intentando comprender de ese modo algunos condicionamientos culturales en los que se insertan los nuevos escenarios.

\section{Abstract}

This paper analyses a set of emergent social issues, which are featured by new conflicts and structures, but also rooted in permanent cultural basis. The papers starts analyzing the causes of the poverty, which is attributed to a fracture motivated by a crisis on the expectative of social promotion. The aim is to understand the ways that the stratification adopts in Chile and the new conflicts that underpin those ways of stratification. Likewise, the paper explores an issue that is assumed as relevant to be themed with more details: the social issue within the framework of the territorial forms of distribution of the population in Chile, in which an imbalance between the administrative and the material reality becomes evident. Finally, the paper analyses the issue of the discrimination and authoritarianism, seeking to understand some of the cultural constraints in which the issues analyzed in this paper are inscribed.

\footnotetext{
1 Agradezco encarecidamente la colaboración de Silvia Ordenes en la discusión y elaboración de este artículo. Es pertinente señalar que las reflexiones y argumentos aquí señalados constituyen esbozos de argumentos de amplio alcance e impresiones sumarias de investigaciones en curso. Cada eje de este artículo requiere todavía mucho más detalle en su enunciación. Sin embargo, ha parecido relevante hacer notar la convergencia de estos diferentes temas como elementos que hacen pensar en una nueva cuestión social y, dado aquello, se ha asumido la importancia de revisarlos a la manera de este documento.

2 Profesor del Departamento de Sociología de la Universidad de Chile. Director de la Revista de Sociología.
} 
Revista de Sociología 21 / 2007 Chile Hoy

Facultad de Ciencias Sociales - Universidad de Chile

\section{Nueva Cuestión Social: Estratificación y Conflictos}

Intentamos formular el paso de la cuestión social de los 90 -la pobreza como estado de necesidad socioeconómica aguda, dura y masiva, que cristalizó en la mítica figura de los 4.000.000 de pobres- a una nueva cuestión social -la de la estratificación de la sociedad, como capas infranqueables de privilegios -por arriba- y de exclusiones por abajo-.

Para abordar este tránsito se hará uso de ciertas metáforas que permiten aclarar el panorama conceptual de un conjunto de fenómenos cuyo tratamiento parece requerir el uso indirecto que el recurso literario posee.

\section{Metáforas: muros, fronteras, limbo.}

Comienza a desarrollarse una zona densa y variada, pero estructuralmente definida, como una tensión, un movimiento.

Tres metáforas, señalamos, pueden servir para ilustrar ese rasgo inter-medio y sus múltiples conexiones de sentido.

El muro dice bien lo que hay de separación y al mismo tiempo contacto. Como la antigua noción de lo liminar ${ }^{3}$ el muro une y separa, divide pero no evita completamente el contacto, así no sea mas que por no poder dejar de indicarlo; como si al impedirlo en un plano, lo instalara en otro. Los muros son el modo en que los que lo hicieron piensan de, y no pueden dejar de pensar en, los que están al otro lado. ${ }^{4}$

La frontera es también una metáfora para una suerte de extranjería interna social ${ }^{5}$, como ciudades que no alcanzan a constituir unidad, y que parecen construidas sobre una desigualdad que las parte. Pero en todas las fronteras hay pasos, idas y vueltas, zonas por ello fronterizas en que lo que comanda no es el estar acá o allá, sino en el traspaso continuo de esas líneas. Algo así ocurre también con la línea de pobreza. No es infrecuente que una misma persona sea, por fases de su vida, pobre y luego salga de aquella situación, pero también recaiga en la misma. ${ }^{6}$ Así, en vez de línea, pudiera mejor decirse banda o zona para contener la ondulación en torno a la llamada línea. Y esto, el carácter reversible. No es sino una parte del asunto que deja complicada la representación lineal que ha cristalizado, a veces, como si fuera "real".

\footnotetext{
3 Al respecto el trabajo de Gabriel Gatti, "Las identidades débiles", CIS. España, 2006, donde muestra la consistencia en lo liviano o procesal, frente a la rigidez y pretensión ideológica y "sociológica" de la identidad reafirmada, o identidades fuertes. Lo mismo en el estudio de Marco Ensignia sobre la Puerta de Morandé 80, a la que analizó en su función liminar, simbólicamente necesaria para el relato profundo de la dictadura.

$4 \quad$ Las metáforas a veces parecen materializarse, como el caso del muro en la comuna de Lo Barnechea hace algunos años.

$5 \quad$ Como si alguna no lo fuera.

6 "Trayectorias de pobreza. Estudio dinámico de la CASEN:", Universidad de Chile. Mideplan, equipo

dirigido por el autor y con el apoyo de Marcelo Astorga, Gonzalo Rovira y Fabián Guajardo.
} 
La metáfora más fuerte puede ser la del limbo con lo que significaba también de ni aquí--ni allá, ni a salvo ni condenado.

Las tres metáforas muestran el mismo movimiento, la misma apertura o tensión: la misma forma de la cuestión social.

\section{Entre líneas: de la pobreza a la no inclusión.}

Estamos hablando de lo que puede definirse como la zona que está entre la línea de la pobreza y la línea de la inclusión social plena.

Se trata del conjunto de ciudadanos/as que no siendo ya pobres, o no siéndolo de modo permanente, no alcanzan sin embargo a solventar su plena inclusión social.

Dependen del Estado para su educación, salud y vivienda. Y en esa dependencia, particularmente en el ámbito de la educación, quedan confinados a un resto de promoción prometida y negada. ${ }^{7}$

Son la forma de los nuevos asalariados, semi-asalariados, que como los temporeros de la pisci-silvo-agricultura oscilan entre la inclusión en verano cuando compran y consumen, reciben tarjetas, imponen, etc.- y la exclusión en invierno -donde muchas veces recaen en la pobreza y deben acogerse al régimen social de protección. Quedan así nombrando lo social, de lo que hablan las Políticas Sociales: lo que es social por insolvencia respecto a los parámetros básicos de la "clase media" o mayoría cualitativa de la sociedad.

Ni pobre ni integrado, oscilando entre una fase y otra, como identidad y figura alterna, uno y otro. Lo mismo globalizado que expulsado, modernizado que descalificado, empleado y desempleado. ${ }^{8}$

Pero es también el caso de los contratistas ${ }^{9}$ en general, que lo mismo puede decirse están empleados, que lo están en un modo que no termina por cuajar en una integración simbólica y socioeconómica plena.

No es distinto, creo, lo que late y estalla en el malestar popular con la escuela, cuya manifestación fue la todavía reciente revuelta de los pingüinos.

$7 \quad$ La que cantaron Los Prisioneros ya en el lejano, pero actual según se ve, año 1985. Al respecto, Agurto I y otros, Juventud Chilena, Razones y Subversiones; Eco-Fólico-Sepade, Santiago, 1985.

8 Figura social de doble estación, en el que termina por cuajar, en las biografias, la opción de un modelo de desarrollo que vende precisamente esa (contra) estacionalidad. Cuando el negocio estuvo de entrada en el clima y en la latitud, las huellas pueden encontrarse en la misma cíclica de la entrada y salida de los temporeros.

9 Es curioso, y sintomático de la misma irregularidad general ya referida, contratista puede designar, como en el caso de la agricultura, al agente intermediario -y cargar con ello gran parte de las culpas del sistema- o al propio trabajador directo-intermediado (como en el caso de los trabajadores forestales o de la minería, donde el nombre del empleador directo (el contratista) nombra también el productor indirecto (contratado). Pero el ruido es sólo en el dignificante, pues el significado en un caso y otro es el mismo: trabajadores no de planta; empleos, puede decirse, que no echan raíz. 
ReVista de Sociolocía 21 / 2007 ChILe Hoy

Facultad de Ciencias Sociales - Universidad de Chile

Por doquier se manifiesta la misma cuestión: un nueva fractura social, que ya no traza la frontera entre los necesidades básicas o cuasi biológicas - como la miseria de la que sabíamos en los sesenta-, sino mas acá, entre los que no pueden auto valerse en los mercados de oportunidades, y deben resignarse así a una suerte de renuncia a la promoción, en el mismo tiempo en que podía recibirse de ya no pobre.

\section{La curva ¿normal?}

Los gráficos que se presentan a continuación son un ejercicio para identificar o medir esa zona. Para ellos, ocupamos los datos de Ingresos de la CASEN del 2007, en el siguiente procedimiento:

a) Reunimos (para darle mayor calidad a la muestra y proyección sociológica al dato) cuatro conjuntos de comunas según niveles de ingresos.

\begin{tabular}{|l|l|l|l|}
\multicolumn{1}{|c}{ ABC1* C2 } & \multicolumn{1}{c|}{ C3 } \\
\hline Vitacura & Nuñoa & Puente Alto & La Pintana \\
Las Condes & Santiago & Quilicura & Cerro Navia \\
Lo Barnechea & La Reina & Maipú & San Ramón \\
Providencia & San Miguel & Independencia & Lo Espejo \\
& La Florida & La Cisterna & Renca \\
& & & La Granja \\
\hline
\end{tabular}

* Somos concientes de la fragilidad tal clasificación, y su lógica específicamente mercantil. Sin embargo, dos razones nos llevan a usarla. En primer lugar, pues muestra bien el espejo dominante de la nueva estratificación -socio-económicamente, en el espacio de las representaciones de clase, lo que comanda hoy es el acceso al consumo, y el código usado está hecho para ello. Pero además, nos permite suficientemente una gradación de las diferencias. No se incorpora la categoría E pues se introduciría una dimensión supletoria - comunas rurales- que complica el análisis -aunque en verdad, lo viene a confirmar.

b) Luego, comparamos su estructura de ingresos con la estructura del promedio nacional. Esto es, tomamos por referencia la distribución por deciles a nivel nacional como "fondo" o parámetro de comparación, y proyectamos sobre ella la distribución de los ingresos de los distintos conjuntos de comunas. Queríamos observar como se "defracta" la gráfica normal -si las comunas fueran como el promedio nacional, debieran marcar 10\% en cada uno de los deciles; en lo que sean distintas al promedio nacional, podrá observarse cuál es el grado y sentido de su desviación. Y podremos luego comparar tales desviaciones. ${ }^{10}$

10 El ejercicio tiene de innovación reemplazar lo habitual, que es analizar la distribución por deciles en el contexto de una misma población. En vez, al proyectarlo sobre un promedio nacional, no sabemos como se distribuye el ingreso dentro de una comuna o un grupo de comunas, pero si sabemos lo que aquí nos importa: como se distribuye el ingreso entre los distintos tipos de comunas. Lo que está a la base es la cuestión de la territorialización de la desigualdad, un dato demasiado ostensible como para no considerarlo y cambiar consecuentemente la lógica de los análisis de la inequidad. En el tema, agradezco las conversaciones con Juan Enrique Vega en nuestro intento de discutir la cuestión de la desigualdad territorial. 
Gráfico 1: Individuos de Comunas D, en cada uno de los Deciles Nacionales. Expectativas de promoción social:

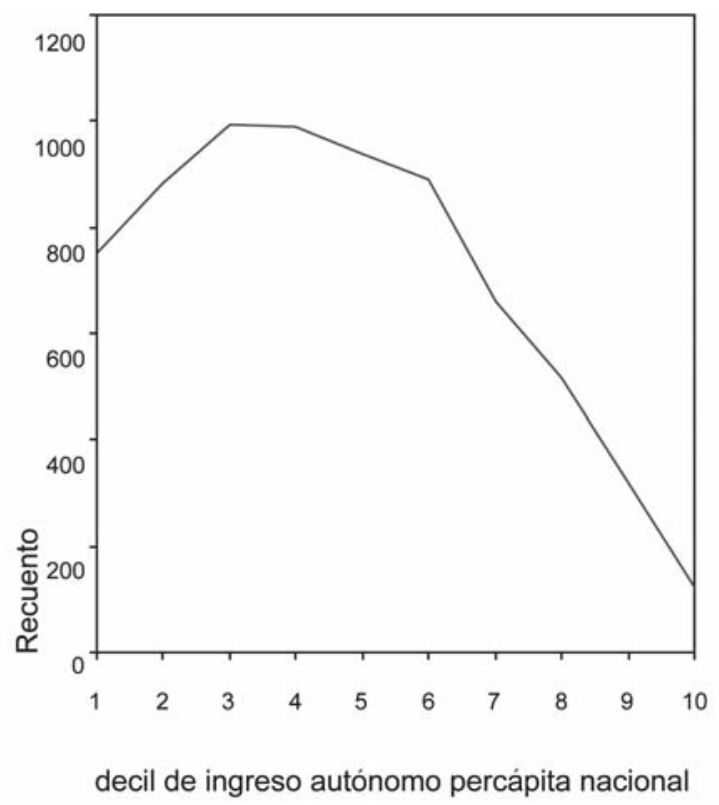

Puede observarse dos inflexiones marcadas: en el decil 3, y en el decil 6, que generan tres zonas:

Zona 1: deciles 1-2 (indigencia, pobreza, inmediatamente por sobre la línea de pobreza) Zona 3-4-5-6: zona promocional (¿transicional?)

Zona 7-8-9-10: zona integrada

De las tres, la sobre-representada es la zona media. No es así una diferencia entre la primera y la tercera lo que define su situación, sino la caída que separa a la zona dos de las tres. Allí se instala el quiebre decisivo de la estructura de expectativas o de las oportunidades o posibilidades. La curva muestra la (im) probabilización de tales posibilidades.

Así, el asunto no está en la sobre-concentración de los habitantes de estas comunas en las zonas de pobreza o indigencia (allí están relativamente más cerca del promedio o $10 \%$ correspondiente), sino en la suerte de meseta a la que se llega en el decil 3 y que termina en una baja abrupta no muy lejos, en el decil 6.

Lo que está en juego es la plausibilidad del intento, y todas sus conexiones de motivación y sentido. ${ }^{11}$

11 La importancia biográfica, en los sectores populares, de la expectativa promocional o surgir fue documentada cualitativa y cuantitativamente por el estudio "El Poder entre los Chilenos" PNUD, Santiago, 2002. 
ReVista de Sociología 21 / 2007 Chile Hoy

Facultad de Ciencias Sociales - Universidad de Chile

Podemos ahora volver a leer el dato, pero con el fondo de las restantes comunas o zonas sociales.

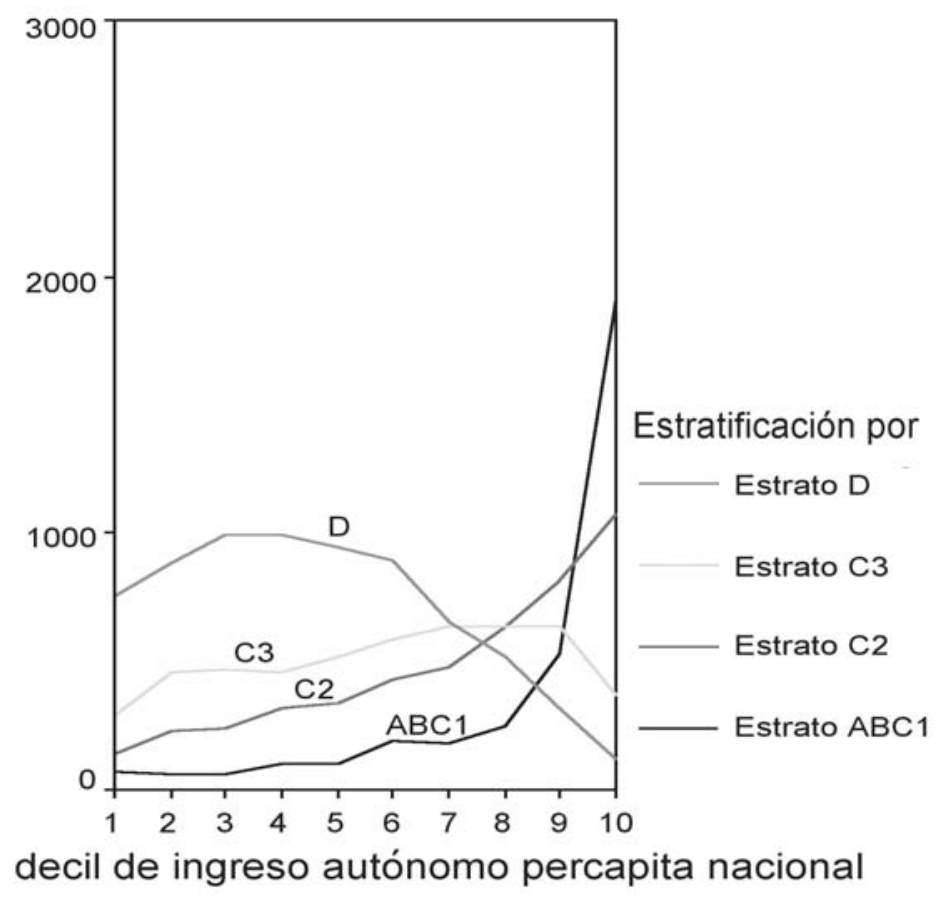

La zona crítica se muestra nuevamente en el paso a la promoción social, o movimiento ascendente después de la pobreza.

Lo que queda graficado es una sociedad efectivamente "estratificada" 12 . De hecho, quien vive en las comunas tipo A prácticamente no tiene como dejar de serlo -al menos sin "cambiarse" de lugar. Así, la segmentación espacial (territorios), viene a ser la prueba urbanística de la estratificación social (estratos).

Ese es precisamente el abismo que señala el limbo: entre comunas y territorios de clases bajas, semi-incluídas y semi-excluídas, y territorios de clases medias y altas.

\section{4. ¿Cómo se progresa? o el desorden de probabilidades en la zona baja.}

Puede incluso decirse de otro modo: ocurre que en la zona baja de la estructura social, digamos la que ocupa los deciles 1 al 6, ni la diferencia educacional, ni ninguna otra genérica, parecen explicar la diferencia de ingresos. Dicho de otro modo, no es determinable, al menos en nuestro análisis, una variable general que explique por qué alguien se encuentre más acá o más allá en la línea de ingresos.

12 Otra metáfora, pero que goza de un aire de cientificidad, y que en nuestro caso señala meridianamente lo que indicamos: allí donde hay estratos, no hay circulación o movilidad. 
Así, en general, alguien con educación media incompleta o hasta completa, puede estar recibiendo menos ingresos que otro sin educación formal. La educación, como variable de orden en los ingresos, comienza a funcionar pasada esta frontera, bastante más acá del cuarto medio y de los 250.000 pesos, ${ }^{13}$ cuando comienzan precisamente las clases medias. ${ }^{14}$

Acaso puede ser esa la frontera: cuando la educación si hace diferencias. Cuando vale. Antes de esa marca, no se la requiere y estar más cerca o más lejos de la línea de la pobreza comienza a depender de factores circunstanciales o directamente personales o sistémico-familiares. ${ }^{15}$

La nueva cuestión social, resultante esta vez no del estancamiento o del atraso o del subdesarrollo, es una problemática que hunde sus bases en el núcleo de la nueva sociedad. No es la pobreza del cesante, como en los 90. Ahora es la situación del empleado, semi-empleado. Se trata de una nueva minoría - cualitativamente hablando- esta vez del propio progreso. ${ }^{16}$

\section{Crítica (parcialmente) en falso: discutir el concepto de pobreza.}

Por lo mismo, falla la crítica a la pretensión oficial respecto a la reducción, y a veces hasta superación, de la pobreza, y que se materializa en la descalificación de los datos de las Encuesta Casen. Como todo instrumento, es criticable y muchas veces discutible en sus indicadores y supuestos. Pero en lo fundamental ha medido bien la disminución efectiva del estado de necesidad declarada de millones de personas.

Es más, la pobreza no sólo ha disminuído cuantitativamente, sino que ha cambiado estructuralmente de posición y significado: si a inicios de los 90 podía designar una nota cualitativa y estructuralmente determinante en el mundo popular, hoy es cada vez más una asunto de "caso", que como tal debe ser abordado ${ }^{17}$.

\footnotetext{
13 Equivale a 500 dólares, y fue señalado como el mínimo ético que debía pagarse a los trabajadores, por un agudo intérprete de las nuevas demandas sociales como lo es la Iglesia Católica.

14 Lo anterior pudimos comprobarlo mediante un análisis de discriminante a los Ingresos de las familias de comunas de provincias rurales -excluidas las ciudades capitales de las mismas, que comienzan a tener un comportamiento semejante las comunas metropolitanas- . Este análisis lo realizamos con ocasión del curso "Nuevos enfoques sobre Pobreza y Ruralidad", producido para el Sistema de formación y capacitación profesional que la Universidad de Chile viene desarrollando hace algunos años con los profesionales del programa Puente-Chile Solidario de Mideplan. Véase, "Perspectivas de trabajo en Ruralidad", Documento de Trabajo, Sistema de Formación y Capacitación Permanente, FACSO- .MIDEPLAN, Agosto 2007, pudiendo seguirse de cerca el caso de las comunas de las provincias de Concepción y de Puerto Montt.

15 Debe ponderarse el juicio, sin embargo, atendiendo a otros valores de la educación formal y completa. De hecho, puede darse el caso de quienes realicen esfuerzos notables por alcanzar tal rango, y no por una pretensión directa de aumento de ingresos, sino de validación social y simbólica. Todavía, pese a todo, el cuarto medio sigue siendo una carta de inclusión, parcial y simbólica, pero igualmente decisiva.

16 "Minorías del Progreso", tesis doctoral del autor, Universidad Complutense, Madrid, 1989.

17 Es por lo demás el buen sentido de la metodología del programa ChileSolidario, que intenta llegar donde las políticas generales (educación, etc.) no alcanzan. Ya no se trata de proteger a todos, sino sólo a aquellos que han quedado rezagados en la antigua miseria.
} 
La crítica puede venir por otro lado: el Chile Hoy, con su incipiente estado de protección social, con sus cifras de ingresos, muestra su falla o fractura en la segmentación cristalizada en estratos y capas que impiden la movilidad, el asenso o el "surgir". Se instala así la evidencia de un orden aristocrático, que señala a los individuos que sus caminos o carreras vienen en lo fundamental definidas por su origen familiar y el consabido carácter "privado-exclusivo" de los colegios de clase alta, y los colegios públicos -excluyentes de los sectores populares.

\section{Nuevos conflictos.}

Por eso son especialmente interesantes, sociológicamente y políticamente, los tres conflictos sociales más relevantes del último año: los conflictos que instalan los temporeros, los contratistas y los escolares son uno solo. Es la demanda por inclusión social, por igualdad de oportunidades o por una democratización de la sociedad. Salir de la pobreza es una cosa, entrar a la sociedad de los integrados es un segundo paso que requiere de otra reforma social, y no sólo de acumulación de crecimiento. Puede decirse incluso que lo que está en juego ni siquiera es la "equidad", sino la crítica de lo que tiende hacia la inequidad absoluta: esto es, cuando la diferencia de oportunidades se traduce en un doble régimen de "incluidos" y "excluidos"; entre unos que las concentran todas, y otros que no tienen ninguna. No es equidad, es menos que eso, y por lo mismo más acuciante: es alguna oportunidad -que haga posible, aunque improbable, el cumplimiento no sólo del deseo social, sino la obligación social de promover. Es ese juego de doble sentido el que atenaza el cuadro: obligados e impedidos al mismo tiempo, la tensión se acumula si no se resuelve o procesa.

Digamos que treinta años después de iniciada la transición a esta nueva economía y sociedad, en que se ha generalizado lo que comenzó en los packings, ahora proyectada a un régimen laboral que recorre toda la estructura socio-productiva (desde los bosques a los supermercados, de los huertos a las minas, y desde los colegios municipales a todos ellos) se puede definir ya la nueva forma, partida, de la sociedad chilena: una sociedad segmentaria, estratificada, organizada sobre el privilegio y la negación. La maduración de esta forma no puede ser distinta a la creación de las bases de una nueva conflictividad social. No en nombre de una utopía de clase -como el socialismo-, pero tampoco solo en nombre de la necesidad -como la demanda del pobre-.

Cuando se produce la protesta de los contratistas, o de los temporeros, o de los pingüinos, estamos asistiendo a la emergencia de un nuevo movimiento o actor social, que presiona ya no en base de la necesidad, sino del derecho social. Cuando esta ocurre, puede hablarse de una nueva cuestión social: del derecho ¿y poder? de un actor de poner en pregunta al orden, y señalarse sus aristas más impresentables e ilegítimas. Desde este tránsito que no conduce, puede fundarse una denuncia cargada de sentido y potencialidad. Es esa queja, también, la base de la desafección profunda de la nueva 
Ni Pobres ni Excluidos: ¿Nueva Cuestión Social?

/ Manuel Canales C.

sociedad respecto a su sistema de representación política. No es casual que todos los conflictos indicados lo hayan sido en distancia y lejanía del sistema de partidos, del gobierno y la oposición. Aquellos siguen en su discusión de la cuestión social de los 80 (la pobreza y la democracia política: esa transición que nunca terminó), cuando la cuestión que late ahora es la de la democracia social y la crisis de expectativas de integración social.

\section{Del territorio: Chile o una loca ¿geografía?}

La segunda cuestión que quiero plantear alude a la representación territorial de la sociedad chilena. Refiero así a lo que entiendo como un desajuste profundo entre la representación formal y administrativa de los territorios, y aquellos en su operar y observarse como las zonas, valles, "partes de Chile", o como quiera llamarse a la territorialidad habitada y reproducida en los sujetos y en las acciones. Un desajuste entre un Chile "administrativo" -como nombran los mapas- y los Chile vividos y gestionados.

En lo fundamental, propongo la crítica de la Regionalización y de su seccionamiento formal y abstracto, externo y plano, y en cambio un enfoque al mismo tiempo más ecológico y más sociológico de pensar los territorios.

En otros términos, se propone que las Regiones corresponden a una lógica en última instancia sino centralista, evidentemente "centralizada": las regiones se ven desde arriba, mejor que desde dentro o de abajo. En vez, se propone una re-observación de la territorialidad asumiendo la perspectiva interna -la misma que devela las distintas lógicas con que se puebla una metrópolis o una provincia rural.

Complementariamente, a la limitación de la región, se observa la de sus contrapartes básicos, los municipios. En vez, se propone ampliar más allá del municipio y encontrarse antes de la región.

\section{Las Regiones están extralimitadas.}

Con la descentralización en las actuales Regiones, el territorio quedó imaginado como un conjunto de lonjas o secciones, que tienden a una misma forma.

Ya era dudoso, desde el inicio, esa lógica de las secciones más o menos uniformes, saltándose como si nada la cordillera de la costa. Más dudoso era - y sigue siendo, también- la increíble tendencia de los ciudadanos a identificarse, ahora con un número romano, donde antes hubo un nombre de lugar, de un ser de ahí, una toponimia muchas veces en el lenguaje del nativo o del fundador, de un observador interno; 
otro signo del autoritarismo nacional y su disposición a la identificación con todo lo que sea, o lo simule, orden. La antigua consigna que don Mariano Picón Salas atribuyera como definición de estos lares, "Chile o la aspiración al orden", parecía quedar cumplida en este mapa simétrico y numeral.

Las regiones constituyen una mirada centralista hacia los territorios. Así se ven los territorios locales desde el Estado central; en ningún caso es la visión de sí mismo de algún territorio local, ni un modo de producir estado central desde abajo.

Como sus insumos cardinales, pueden describirse como una descentralización a la romana, en una lógica de imperio o de control territorial.

Pero lo saben los de la Provincia de Nuble, cuado se les confunde con lo que sea la R.VIII, o los de Aconcagua con la R.V., o como Melipilla con la innumerada, y si nombrada, R.M. O lo sabían los de Valdivia, o los de Arica. Así también los de Pichilemu o los de Cauquenes Maule, que tocaron en suerte ser del otro lado del inmenso monte que más al Sur llaman de Nahuelbuta, y que les separa -y diferencia, identificándolos- de los valles centrales y sus riegos. Pero ahí están, confundidos con Rancagua el primero, y con Talca el segundo.Y es lo mismo, o parecido, valle a valle.

Pero, sin embargo, se mueve. La Loca Geografia ${ }^{18}$ quizá pueda más que la pretendía inteligencia y racionalidad de la Institución geográfica.

Así, contra toda voluntad común, que al parecer sigue valorando en bien tanto orden formal y lineal, comienza a desgranarse la mazorca cuya coronta tiene nombre y estilo autoritario-tecnocrático. En el sur y el norte, las Regiones (estas, habría que decir) comienzan a hacer crisis.

Y comienzan a ocurrir eventos insólitos, bordeando el ridículo, como el desorden gráfico y numeral al que arrastraron las crisis del norte y del sur al sistema de numeración anterior. Pero el absurdo es aún más marcado, pues implica no sólo esta irrisoria secuencia caótico-romana, sino cosas más importantes, como la propia unidad territorial. Así por ejemplo Valdivia debió partirse en dos, creando una nueva provincia, para poder ser "región". Esto es, para poder ser provincia independiente de la región vecina a la que estaba unida más por la fuerza de la regla escolar que por la razón de la provincia, la cuenca o el territorio vivido. ${ }^{19}$

Como fuere, las regiones nombran cada vez menos, si es que alguna vez nombraron algo, un territorio asible desde abajo, y sólo marcan zonas de gestión estatal central.

\footnotetext{
18 Que la geografía de Chile haya sido descrita, casi como acuerdo nacional, con la fórmula de don Benjamín Subercaseux, como un loca, no garantiza que lo sea. Pero pretender reducirla a 13 rayas donde antes ya había cientos de lugares y caminos, historias y sobre todo una racionalidad territorial tras todos ellos, parece ciertamente insensato.

19 He usado esta expresión en "Subjetividades y territorios vividos", PNUD, 2005. Agradezco una vez más a Francisco Ther el conocimiento del concepto.
} 
En suma, lo más sólido de la región termina por ser la Intendencia. Pero poco más allá no hay nada consolidado. Ni identidades, ni sistemas económicos, ni siquiera paisajes ni modos de vida. Después de múltiples intentos de "construir región", seminario a seminario, indagando hasta la porfia en atisbos de identidades o encadenamientos, lo que queda es lo dicho: la huella de esa porfia representada en las Intendencias plenipotenciarias y al mismo tiempo, en lo que hace a la gestión política del territorio - y no sólo a la gestión descentralizada de políticas públicas - impotentes.

Por ello es que propiciar la "participación regional", por ejemplo, puede ser un intento en vano: en el vacío de un sujeto y un actor que pueda orientarse y gestionarse siguiendo los recortes con que ordenó el mapa el planificador central. ${ }^{20}$

\section{Las comunas no alcanzan.}

El otro pivote sobre el que se organiza la gestión territorial es la comuna.Y habría que agregar, para nombrar al inmenso número de ellas, las "comunas chicas" -paradójicamente sin embargo muy extensas-.

La comuna al menos enfoca habitualmente bien un territorio vivido, una zona marcada por paisaje, producción, estilo de vida. Son, incorporando toda la variedad social, territorialmente consistentes y "reales", esto es, operadas y vivenciadas por actores y sus intereses, sujetos y sus discursos, sus ríos y sus cerros.

Pero la escala en la que se componen la geografia humana, tiende a quedar estrecha. Las comunas vecinas no sólo lo son "espacialmente", sino también cultural y económicamente. Aun más, tienden a funcionar en sistemas "intercomunales”, con juegos de poder interno y proyectos de desarrollo posibles sólo en la comarca. Tal comarcalidad queda borrada en esta tendencia a la sujeción de lo comunal a lo municipal.

Así por ejemplo, las tales comunas chicas, debiendo gestionar territorios extensos, tienden a pensarse como unicentradas (en la ciudad comunal) no pudiendo dar cuenta de su territorio real, productivo, histórico, sino sólo como una visión de "exteriores", "afueras" o márgenes.

El modelo se complementa así en la articulación Región-comuna, Intendencia-Municipio, en una asimetría total que no permite en definitiva la transición ni el acople entre el Estado central y lo que puedan ser los estados locales. Desde arriba, la región 20 Por ejemplo, los datos de la encuesta CASEN, que se informa profundamente en términos regionales, no sirve de mucho si no se le recorta por provincias. La cuestión de la pobreza, y de los ingresos, tiende a ser homogénea provincialmente, pero muy heterogénea interprovincialmente. Lo mismo ocurre con los datos de empleo -el valle central no es el secano costero. La confusión puede darse por el caso de Regiones "metropolitanas" que tienen sobre concentrada la población. El caso de las Regiones agrícolas, -o pesqueras, forestales o pecuarias, como es habitual, multi-funcionales - en cambio es muy distinto. Pudiendo ser la misma latitud, no es lo mismo la cota de las aguas a las que se accede, ni los pisos ecológicos en los que se habita. Desde el centro metropolitano, autocontextualizado geográficamente, se trata de detalles. Desde los lugares, se trata ni más ni menos que la ley de las cosas. 
queda muy alta para tocar, puede decirse, el territorio, Desde abajo, la comuna queda limitada para concebirse en el paisaje y país del que es parte. ${ }^{21}$

Lo decía Ricardo Lagos recientemente para explicar la falla institucional en el gran fracaso de la gestión tecnocrática que fue el Transantiago: la falla está en el dibujo del territorio, pues, en cita no necesariamente literal, "la región es muy grande y la comuna es muy pequeña”. Algo como el sistema de transporte no puede sino pensarse desde otro horizonte, precisamente el negado por el sistema región-comuna: la provincia, o cuando menos, un intercomunal coextensivo al sistema.

El fallo en el esquema territorial afecta en este caso específicamente al patrón "metropolitano", al no pensarse a sí mismo como tal -como metrópolis: espacio físico comprimido, enjambre- y en cambio imaginarse como un conjunto de comunas en una región.

Las comunas no sólo son comunas de una región, o incluso provincia, pues:

a) en los territorios metropolitanos - como las grandes ciudades- cada comuna es parte de un conjunto metropolitano -precisamente lo que no es la actual, así llamada, Región Metropolitana;

b) en los territorios "rurales" -que pudiéramos llamar por contraste a los metrópolis, "agrópolis", como en las provincias piscisilvoagropecuarias, las comunas también son parte de conjuntos "comarcales", que componen por razones de poblamiento de un entorno natural, extendido y organizado oro e hidrográficamente, y habitado, trabajado y hablado por generaciones desde, muchas veces, varias fases históricas y hasta civilizatorias. Son las zonas, y las conjunciones de zonas en la cartografia nacional que está por hacerse. ${ }^{22}$

Pero es también lo que saben, o comienzan a saber, los nuevos actores sociales territoriales. Ninguno de ellos se parea con la intendencia regional ni el municipio comunal. Siempre tienden, como en el caso paradigmático de los movimientos ambientalistas, a proyectarse intercomunal o provincialmente, siguiendo esa vieja referencia que son las cuencas y sus aguas. ${ }^{23}$

\footnotetext{
21 Paisaje, país, paese, paisano: del campo, de ahí, de la zona, "campesino".

22 Queda planteada de fondo una cuestión sociológicamente mayor: la sociología de los territorios no puede seguir operando con un concepto que aplane la diferencia entre dos patrones de territorialización sustantivamente diferentes. Puede definirse territorio como el "poblamiento de un entorno", o como un "entorno poblado". Pues bien, en el caso de los territorios metropolitanos - como el de las grandes ciudades- cabe decir que se trata de un territorio "artificial", o lo que es lo mismo, de poblamientos que se instalan en un entorno auto referido, tal que sus preguntas territoriales son habitualmente interiores y de espaldas a lo que haya, o dejen, de cuenca. Territorios, como patrón de poblamiento por compresión del espacio físico o natural. En las antípodas, puede identificarse el poblamiento de entornos naturales, que pudiera llamarse territorios rurales, o para jugar por posición con metropolitas, como agrópolis: mientras la primera concentra población, la segunda la pluricentra a lo largo y ancho del curso de las aguas. Dos lógicas distintas: una cuenca mercantil y una cuenca fisica. Hasta ahora, territorio es lo mismo y uno solo. La posibilidad de volver a pensar el territorio supondrá razonablemente trazar esta diferencia, que siga a la doble lógica con que habitamos, y destruimos no pocas veces, los espacios que poblamos

$23 \mathrm{Al}$ respecto, pueden consultarse los trabajos de M. Rodríguez, coordinador del programa de Doctorado
} 


\section{3. ¿Y la provincia?}

La invisibilización de la provincia, en nuestro caso, viene a reforzar, y es reforzada por, una paralela invisibilización de la nueva ruralidad. Esta, como la antigua, viene organizada en una proyección territorial como la de las cuencas, en el notable concepto del paisaje rural - un sistema socio productivo articulado con una biodiversidad-. Ha ocurrido a partir de los 70 y 80 , un re-poblamiento, por concentración de crecimiento vegetativo poblacional que en las cinco décadas previas se volcaban casi completamente en la ciudades metropolitanas industriales, ahora en las dinámicas agro-urbes y sus nuevas poblaciones de trabajadores muchas veces temporeros.

Ni pudiendo reconocerse a sí misma como la antigua ruralidad, no puede tampoco concebirse en lo que comienza a ser su modo de proyección y concresión más potente, como es el territorial. Ni ruralidad antigua de los fundos, ni nueva provincia.

Puede formularse así la segunda cuestión: el actual ordenamiento territorial construido sobre el par Región-Comuna, no se sostiene ya ni como razonable ni como útil ni apropiado. En vez, pueden estarse fraguando nuevos regresos al antiguo saber que conocía al territorio en las macro-zonas y sus valles transversales, provincianos. ¿Cuánto demorará en hacer crisis el mapa regional? ¿Habrá actores suficientemente globalizados y modernos para asumir una nueva provincia revalorizada y activada? ¿O se seguirá en ese tic tan provinciano antiguo de querer ser metrópoli?

Como fuere, es evidente que sería muchísimo más potente, en vez de propiciar como se hace ahora, la elección de "Consejeros Regionales", el reforzar y entregar un protagonismo a la actual desvalorizada y despotenciada "gobernación” provincial.

Quizás entonces, habrá que pasar de la geografia administrativa, a una geografia humana y política, así tenga que ser más loca y local.

\section{Tercera cuestión: del Chile autoritario y discriminador.}

Una nueva cuestión cultural parece también estar fraguándose. Trátase de aquélla que pone el acento en la cuestión del otro y su reconocimiento, así como en la cuestión de la libertad y sus responsabilidades.

En sucesivas encuestas que hemos realizado con la Fundación IDEAS, para medir autoritarismo y discriminación, encontramos siempre la misma pauta:

a) los chilenos son más autoritarios que discriminadores.

b) Los chilenos, en lo que tienen de discriminadores, lo son sobre todo "claen Sociología de la Universidad de Valencia, que ha estudiado la dimensión ambiental de la nueva conciencia territorial. La pista que provee es que para comprender la nueva ruralidad, al menos en el caso de España, hay que buscarla preguntando por los movimientos territoriales. Tal idea fue base para mi propio trabajo en esta línea. 
sistas", un poco menos, pero más que suficientemente, racistas, y cada vez menos machistas.

c) Lo que explica, estadísticamente el que sea mas o menos autoritario o mas o menos discriminador, es la misma variable Educacional (formal) o lo que viene a ser lo mismo, el nivel socioeconómico.

d) No se es discriminador de una u otra minoría, sino que precisamente el juego consiste en discriminarles a todas.Y así, el machista es también racista y clasista, y todos ellos autoritarios, dogmaticos e intolerantes. No se trata por tanto de nada que tenga ver con las minorías, sino con la actitud o perspectiva de mayoría que un sujeto se arroga para minorizar a otros, y así enseñorearse e imperar.

Se construye sobre estas bases un orden y una lógica social que complica cualquier despliegue pleno del otro vector nacional -el democrático y tolerante y no discriminador-. Como una permanencia de "dos almas", que no se resuelve.

Pero es esa "mentalidad" autoritaria y discriminadora, la que puede sostener el consabido "uniformismo" y "jerarquismo" nacional.

Desde siempre se ha sabido que el que se sale de la línea es objeto de vigilancia y control. Que el uniforme se agradece, y no sólo se acepta, para la primera infancia y hasta para toda la vida social. Así resulta ostensible para cualquier observador externo, en la sala cuna, el taller, o el metro.

Sólo durante el período universitario se tolera la no uniformidad, pero aún allí predominan formas y estilos acotados y muy finitos.

Se constata que la convivencia se percibe amenazada por una suerte de perversión autoritario-sumisa, que conspira contra la posibilidad de la diversidad y la creatividad, por mal ejercicio del poder y pronta disposición al obedecer. Como en la imagen del gallinero, la escala nacional se presenta como una línea de descarga en que el de arriba sojuzga al inferior inmediato, y este al siguiente, hasta llegar al final y la búsqueda de nuevos receptores del castigo ritual en los inmigrantes populares.

Pero podemos todavía formular dos preguntas adicionales.

¿Por qué son más altos los valores en autoritarismo que en discriminación? La respuesta parece estar en la misma causa que explica su variación interna. El colegio, que hace la diferencia en la discriminación, no la hace tan efectivamente en el autoritarismo. Y así parece razonable toda vez que el sistema escolar está diseñado, al menos en las décadas anteriores sobre un ideario ilustrado y racional -en clave de derechos humanos- que objeta de entrada el prejuicio racista, clasista, machista 
o cualquier otro. Por ello, no es extraño que por ejemplo el racismo doctrinal no sea tan alto $^{24}$. En cambio, el mismo colegio no ha tenido un equivalente respecto a la cuestión del uniforme y la jerarquía. Así, se trata de colegios "ilustrados", pero igualmente "disciplinantes" y no centrados en el desarrollo de la autonomía de sus estudiantes y profesores. Son colegios "racionales", pero ordenados. No se dice la discriminación, pero se hace la autoridad. Todavía en nuestras aulas hay quien piensa que hay preguntas tontas.Y todavía en las mismas aulas, no hay talleres de educación sexual.

La segunda pregunta que cabe hacerse es por qué este encuentro y conflicto entre dos almas tan irreductibles, no la vemos convertida en agenda y lucha declarada.

Quizás la respuesta está por una representación política desplazada y paradójica de la sociedad en este punto. Así, las doctrinas de los actores políticos más de izquierda, tienden a enajenar su base sociológica popular. Lo mismo ocurre a la posición contraria. La doctrina de la derecha no puede completamente desplegarse pues se enajenaría su base sociológica de clases medias liberales y modernas. Así, queda revuelto el mapa cultural y político, y de alguna manera todos pierden. Siendo el caso, puede intentarse el ya conocido uso chileno: se instala un lugar intermedio, sotto vocce, en que los liberales reconocen un derecho de veto en los conservadores y éstos una aceptación a la fuerza de las tendencias que no pueden controlar. Pero el terreno intermedio está plagado de gestos que revelan lo insostenible: ahí está la historia de las JOCAS, su escándalo y su derrota -hasta ahora, pues son la ruta lógica, dialógica si se prefiere, de abordar el asunto- para indicar ese sometimiento en última instancia al veto, aún a costas de la salud pública y de los derechos de los jóvenes -por lo demás, valores latamente nombrados y honestamente queridos por el sistema político.

Queda puesta así una tercera cuestión: ¿Se desatará el nudo ideológico que hoy retienen el proceso de emancipación cultural por el veto autoritario? ¿Se hará la crítica del racismo y del clasismo, al modo que se hizo por el movimiento de mujeres con el machismo? ¿Podremos los chilenos alguna vez asumirnos mestizos y populares, o seguirá siendo la norma el parecerse al que te niega?

24 Aunque lo es más respecto del pueblo mapuche que de otras etnias lejanas, y que además, aunque no doctrinalmente, sigue operando en el inconsciente y sus gustos, como lo revela el increíble culto del biotipo en las llamadas pelolais y su gratísima aceptación por la prensa y el decir popular. 